Review began 08/16/2021 Review ended 08/19/2021 Published 08/23/2021

๑) Copyright 2021

Almofareh et al. This is an open access article distributed under the terms of the Creative Commons Attribution License CC-BY 4.0., which permits unrestricted use, distribution, and reproduction in any medium, provided the original author and source are credited.

\section{Zinner Syndrome: A Case Report of a Rare Etiology of Infertility}

\author{
Abdulrhman M. Almofareh ${ }^{1}$, Khalid M. Aljuaid $^{1}$, Sewar A. Almirabi ${ }^{2}$, Yazn M. Hakami ${ }^{1}$, Amin M. Alwan ${ }^{1}$ \\ 1. Urology, Batterjee Medical College, Jeddah, SAU 2. Urology, Ibn Sina National College for Medical Studies, Jeddah, \\ SAU \\ Corresponding author: Abdulrhman M. Almofareh, abdulrhmanalmofareh@mail.com.tr
}

\begin{abstract}
Infertility is a common medical issue with different etiologies. It can be related to female factors, male factors, or factors related to both partners. We report the case of a 35-year-old male patient who presented with primary infertility for 10 years. He was otherwise healthy with unremarkable past medical history. Physical examination revealed normal external genitalia with both testes were normal in size. Basic semen analysis revealed decreased sperm volume and sperm count. Abdominal ultrasound examination revealed an absent right kidney. Subsequently, the patient under a computed tomography scan that confirmed the right renal agenesis and demonstrated a well-defined right seminal vesicle cyst. Such findings were consistent with the diagnosis of Zinner syndrome. He underwent aspiration of the cyst that resulted in improvement in the sperm parameter of basic semen analysis. The case demonstrated a rare etiology of male infertility that was successfully managed conservatively. Despite its rarity, physicians should consider the developmental anomalies of the genitourinary system when encountering patients with infertility.
\end{abstract}

Categories: Family/General Practice, Radiology, Urology

Keywords: unilateral renal agenesis, male factor infertility, seminal vesicle cyst, zinner syndrome, case report

\section{Introduction}

Infertility is a prevalent health condition affecting up to $10 \%$ of the population and has significant psychological, economic, and medical implications [1]. It is defined as the inability of a couple to conceive after 12 months despite regular sexual intercourse without the use of contraceptives [1]. Epidemiological studies revealed that up to $90 \%$ of couples usually conceive within the first year of attempted conception [2]. Infertility is a unique condition as it could be related to female factors, male factors, or factors contributed by both partners. Male infertility could be due to several etiologies, including endocrine disorders, primary testicular defects in spermatogenesis, sperm transfer disorders, or idiopathic male infertility. Herein, we present the case of a middle-aged man with primary infertility who was found to have a rare condition, known as Zinner syndrome, which is defined as the presence of a congenital seminal vesicle cyst.

\section{Case Presentation}

We report the case of a 35-year-old male patient who presented to the infertility clinic with primary infertility for 10 years. He has a regular sexual activity every three days with no difficulties related to libido or potency. He had no urinary complaints. He has no history of smoking or alcohol drinking. The family history was unremarkable for infertility. The past medical history was non-contributory.

His spouse is a 30-year-old woman with no health issues. She has regular menstrual cycles with no history of dysmenorrhea or menorrhagia. She had not undergone any operations in the past and had no history of sexually transmitted diseases. They reported that the problem of infertility was having a significant psychological impact on their lives.

Physical examination of the patient showed normal abdominal and genital examination with both testes were in size. Physical examination of the spouse revealed a soft abdomen with no masses or tenderness. Bimanual pelvic examination was normal.

Basic semen analysis was performed for the patient, which revealed a normal semen color and viscosity, a semen volume of $2 \mathrm{ml}$, and a sperm count of 10 million. Basic laboratory investigations, including hematological and biochemical tests, were within normal limits. Otherwise, his spouse had a normal hormonal profile with an unremarkable ultrasonic examination of the pelvis. Additionally, her hysterosalpingography examination showed a normal uterus and patent fallopian tubes.

Subsequently, the patient underwent a bedside ultrasound which revealed an absence of the right kidney. Computed tomography examination confirmed the finding of right renal agenesis and a well-circumscribed cyst in the pelvis (Figure 1,2). Such findings were consistent with the diagnosis of Zinner syndrome. 


\section{Cureus}

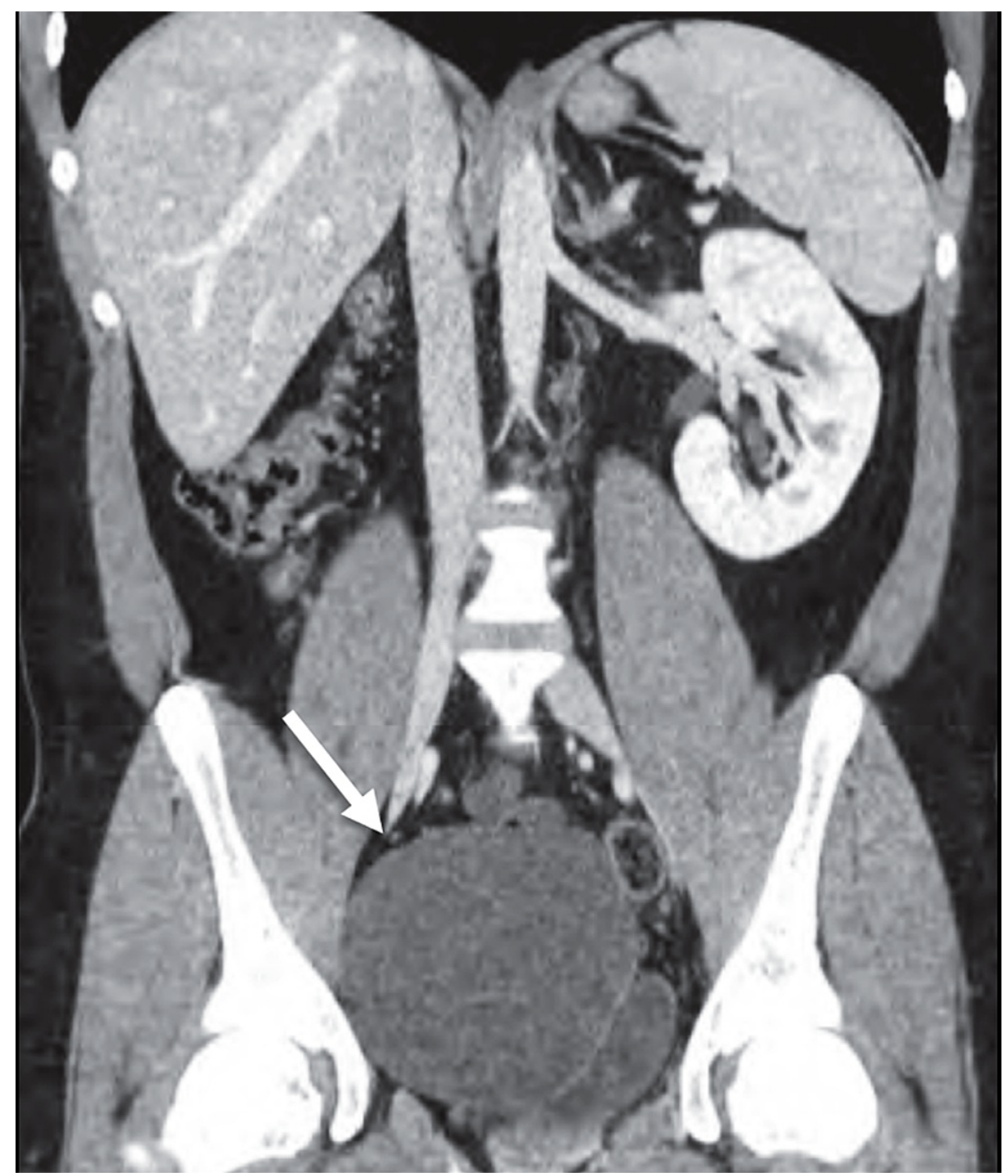

FIGURE 1: Coronal computed tomography image.

Coronal computed tomography image of the abdomen showing a right-sided well-defined cyst in the pelvis (arrow) with an absent right kidney. 


\section{Cureus}

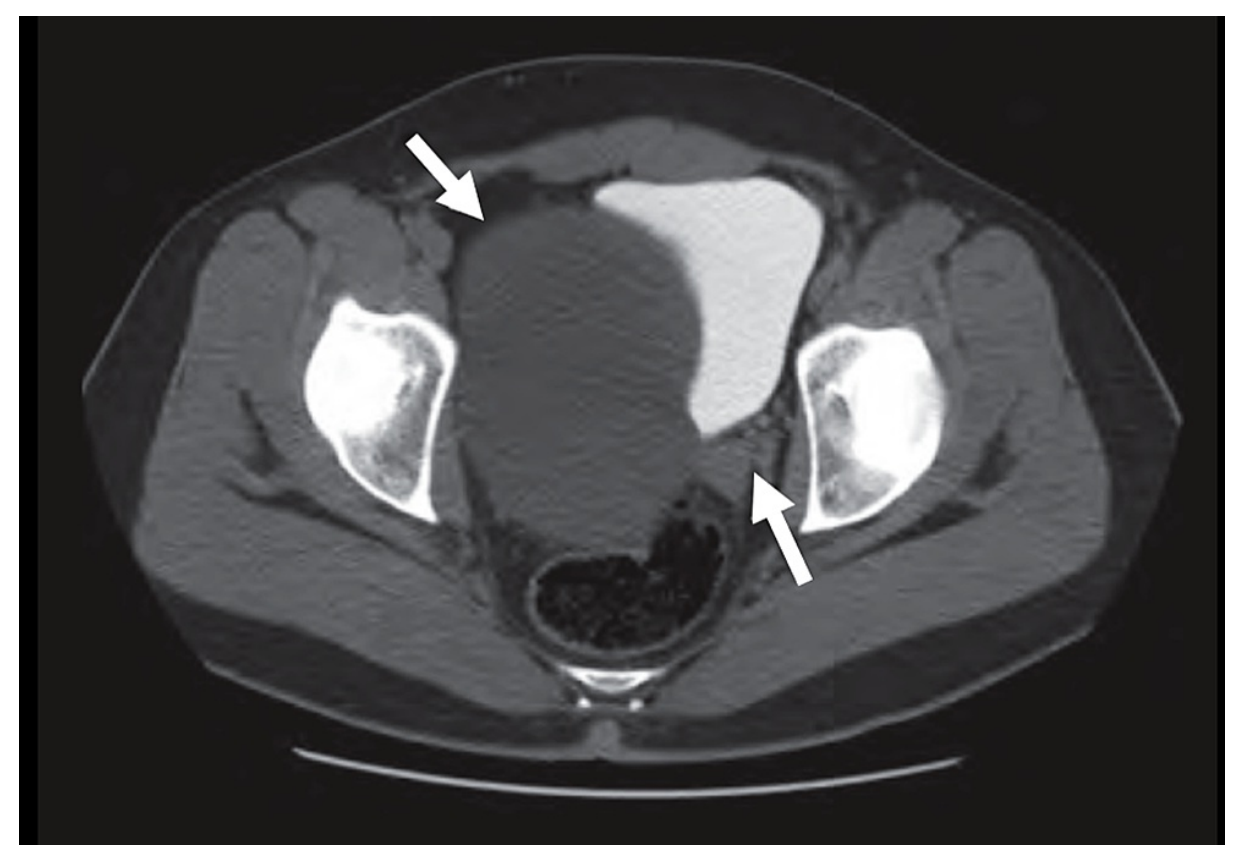

\section{FIGURE 2: Axial computed tomography image.}

Axial contrast-enhanced computed tomography image of the pelvis (excretory phase) showing a well-defined cyst in the pelvis displacing the urinary bladder to the left (arrows).

Accordingly, the patient was planned to have a transurethral aspiration of the seminal vesicle cyst combined with minocycline sclerotherapy. Analysis of the aspirated fluid revealed spermatozoa. A few months later, the patient repeated the basic semen analysis and showed improvement in the sperm parameters.

\section{Discussion}

We reported a case of Zinner syndrome, which is a rare congenital genitourinary anomaly that was first described in 1914 [3]. It is characterized by a trial of ejaculatory duct obstruction, seminal vesicle cyst, and ipsilateral agenesis. The clinical manifestation of Zenner syndrome includes dysuria, frequency, perineal pain, and infertility.

The common embryologic origin of the genital and renal systems explains the association of seminal vesicle cyst and the ipsilateral renal agenesis in this syndrome. It is thought to be related to an in-utero insult resulting in maldevelopment of the distal Wolffian duct. Hence, some authors describe this syndrome as the male counterpart of the Mayer-Rokitansky-Kuster-Hauser syndrome [4].

The diagnosis of Zinner syndrome can accurately be reached by imaging. Magnetic resonance imaging is the modality of choice to evaluate the anatomy of the genital tract. However, since it was not available in our institution, a computed tomography scan was performed.

The management of Zinner syndrome depends on the clinical manifestation. Regular surveillance is sufficient for asymptomatic patients. Aspiration of the seminal vesicle cyst can be curative as in the present case. Surgical treatment and assisted reproductive techniques, such as in-vitro fertilization can be offered if the conservative management was not successful [5]. Laparoscopic management of the cyst seems a feasible surgical option [6].

\section{Conclusions}

The case demonstrated a rare etiology of male infertility that was successfully managed conservatively. Despite its rarity, physicians should consider the developmental anomalies of the genitourinary system when encountering patients with infertility. Imaging modalities have the ability to make an accurate diagnosis of such anomalies.

\section{Additional Information \\ Disclosures}

Human subjects: Consent was obtained or waived by all participants in this study. Institutional Review Board of KSAU issued approval N/A. Case reports are exempted from institutional review board approval as 
per our institutional guidelines provided that the patient's details are anonymized and a written informed consent is taken. Conflicts of interest: In compliance with the ICMJE uniform disclosure form, all authors declare the following: Payment/services info: All authors have declared that no financial support was received from any organization for the submitted work. Financial relationships: All authors have declared that they have no financial relationships at present or within the previous three years with any organizations that might have an interest in the submitted work. Other relationships: All authors have declared that there are no other relationships or activities that could appear to have influenced the submitted work.

\section{References}

1. Chandra A, Copen CE, Stephen EH: Infertility and impaired fecundity in the United States, 1982-2010: data from the National Survey of Family Growth. Natl Health Stat Rep. 2013, 2013:1-18.

2. Slama R, Hansen OK, Ducot B, et al.: Estimation of the frequency of involuntary infertility on a nation-wide basis. Hum Reprod. 2012, 27:1489-98. 10.1093/humrep/des070

3. Slaoui A, Regragui S, Lasri A, Karmouni T, El Khader K, Koutani A, Ibn Attya A: Zinner's syndrome: report of two cases and review of the literature. Basic Clin Androl. 2016, 26:10. 10.1186/s12610-016-0037-4

4. Shebel HM, Farg HM, Kolokythas O, El-Diasty T: Cysts of the lower male genitourinary tract: embryologic and anatomic considerations and differential diagnosis. Radiographics. 2013, 33:1125-43.

10.1148/rg.334125129

5. Pereira BJ, Sousa L, Azinhais P, et al.: Zinner's syndrome: an up-to-date review of the literature based on a clinical case. Andrologia. 2009, 41:322-30. 10.1111/j.1439-0272.2009.00939.x

6. Seo IY, Kim HS, Rim JS: Congenital seminal vesicle cyst associated with ipsilateral renal agenesis . Yonsei Med J. 2009, 50:560-3. 10.3349/ymj.2009.50.4.560 